\title{
Violência doméstica e sofrimento ético-político: redes de cuidados informais de usuárias do centro de atenção psicossocial e do centro de referência em assistência social no contexto brasileiro
}

\author{
Uiolencia intrafamiliar y apoyo ético-político: redes de atención informal \\ de usuarios del centro de atención psicosocial y del centro de referencia \\ de atención social en el contexto brasileño \\ Domestic Uiolence and Ethical-Political Support: Informal Care networks \\ of Users of the Psychosocial Care Center and the Social Care Referral \\ Center in the Brazilian Context
}

\author{
Rafaela Gomes \\ Ana Kalliny Severo \\ Kyra Kadma Silva Fernandes de Medeiros \\ Luiza Celeste Palhares Bezerra \\ Eslia Maria Nunes Pinheiro \\ Universidade Federal do Rio Grande do Norte
}

Doi: https://doi.org/10.12804/revistas.urosario.edu.co/apl/a.10358

\section{Resumo}

O presente estudo objetivou identificar e discutir as redes de cuidados informais de mulheres em situação de violência doméstica, e que são usuárias de serviços de atenção especializada em saúde mental e assistência so- cial de uma cidade do interior do Nordeste. A perspectiva teórico-metodológica adotada foi a Análise Institucional, com ênfase na pesquisa-intervenção, que permite visualizar as forças que tendem à reprodução (instituído), e as que tendem à transformação de determinado

Rafaela Gomes ORCID ID: https://orcid.org/0000-0002-7429-5900 Ana Severo ORCID ID: https://orcid.org/0000-0002-9548-6394 Kyra Medeiros ORCID ID: https://orcid.org/0000-0003-4905-8636 Luiza Bezerra ORCID ID: https://orcid.org/0000-0003-4978-1509 Eslia Pinheiro ORCID ID: https://orcid.org/0000-0002-1782-4933 Dirigir correspondência à Rafaela Gomes. Endereço: Rua João Florentino de Medeiros, 397, Cruzeta, Rio Grande do Norte, 59375-000, Brasil. Correio eletrônico: rafaela97gomes@gmail.com

Para citar este artigo: Gomes, R., Severo, A. K., Medeiros, K. K. S. F., Bezerra, L. C. P., \& Pinheiro, E. M. N. (2021). Violência doméstica e sofrimento ético-político: redes de cuidados informais de usuárias do centro de atenção psicossocial e do centro de referência em assistência social no contexto brasileiro. Avances en Psicología Latinoamericana, 39(3), 1-16. https://doi.org/10.12804/ revistas.urosario.edu.co/apl/a.10358

Esta pesquisa foi aprovada por Comitê de Ética competente e segue as orientações dispostas na resolução 510/16 do Conselho Nacional de Saúde. 
fenômeno (instituinte). Para tanto, foram realizadas, ao todo, seis rodas de conversa com os profissionais dos serviços acerca da temática da violência doméstica, e entrevistas com quatro mulheres escolhidas nas rodas de conversas. Além disso, outros instrumentos utilizados neste estudo foram o diário de pesquisa, os ecomapas e os prontuários dos serviços. Dessa maneira, a análise dos dados permitiu identificar três analisadores acerca do que tem permanecido e o que tem se transformado nas redes informais de cuidado de mulheres em situação de violência doméstica. O primeiro analisador se refere à configuração da rede informal das mulheres a partir da violência doméstica; o segundo consiste na relação entre a rede formal e informal; e o terceiro, nas redes quentes e vivas possivelmente construídas com a contribuição do processo de pesquisa. Destaca-se, ainda, o importante papel da rede informal como dispositivo de cuidado às mulheres em situação de violência doméstica e sofrimento ético-político, na medida em que se apresenta como rede capaz de contribuir na participação e autonomia das usuárias no cuidado em saúde.

Palavras-chave: violência doméstica; saúde mental; redes formais e informais de cuidado.

\section{Resumen}

Este estudio tuvo como objetivo identificar y discutir las redes de atención informal de mujeres en situación de violencia intrafamiliar, usuarias de servicios de atención especializada en salud mental y asistencia social en una ciudad del interior del nordeste de Brasil. La perspectiva teórico-metodológica adoptada fue el análisis institucional, con énfasis en la investigación intervencionista, que permite visualizar las fuerzas que tienden a la reproducción (establecidas) y las que tienden a transformar un fenómeno dado (instituyendo). Para ello, se realizaron un total de seis círculos de conversación sobre la violencia intrafamiliar con profesionales del servicio, y se realizaron entrevistas a cuatro mujeres elegidas en los círculos de conversación. Además, otros instrumentos utilizados en este estudio fueron el diario de investigación, los ecomapas y los registros de los servicios. Así, el análisis de los datos permitió identificar tres analizadores sobre lo que quedó y lo que se transformó en las redes informales de atención a mujeres en situación de violencia intrafamiliar. El primer analizador se refiere a la configuración de la red informal de mujeres basada en la violencia doméstica; el segundo consiste en la relación entre la red formal e informal; y el tercero, en las redes cálidas y vivas posiblemente construidas con el aporte del proceso de investigación. También se destaca el importante papel de la red informal como dispositivo de atención a las mujeres en situaciones de violencia intrafamiliar y sufrimiento ético-político, ya que se presenta como una red capaz de contribuir a la participación y autonomía de las usuarias en la atención de la salud.

Palabras clave: violencia doméstica; salud mental; redes de atención formales e informales.

\section{fibstract}

This study aimed to identify and discuss the informal care networks of women in situations of domestic violence who are users of mental health and social assistance specialized care services in a city of the interior of Northeast Brazil. The theoretical and methodological perspectives adopted were the institutional analysis with an emphasis on intervention-research, which allowed to visualize the forces that tend to the reproduction (instituted) and those that tend to transform a certain phenomenon (instituting). To this end, six meetings were carried out with the professionals of the domestic violence services, plus interviews with four women from the meetings. Also, other instruments used in this study were the research diary, ecomaps, and medical records of the services. Thus, the data analysis allowed to identify three analyzers about what has remained and what has been transformed in the informal networks of care for women in situations of domestic violence. The first analyzer refers to the women's informal network configuration based on domestic violence. The second consists in the relationship between the formal and informal network, and the third consists in the warm and living networks possibly built with the contribution of the research process. It is also worth noting the important role of the informal network as a care device for women in situations of domestic violence and ethical-political 
suffering, as it appears as a network capable of contributing to the participation and autonomy of users within healthcare.

Keywords: Domestic violence; mental health; formal and informal care networks.

Dados divulgados pelo Instituto de Pesquisa Econômica Aplicada (IPEA), no Atlas de Violência de 2020, apontam que 4.519 mulheres foram assassinadas no Brasil em 2018 (IPEA, 2020). Apesar da existência de leis, como a Lei $n^{\circ} 11.340 / 06$ (Lei Maria da Penha), a prevenção e a punição da violência contra a mulher ainda encaram desafios, como a dificuldade de se instituir uma rede de enfrentamento bem estruturada (Pasinato, 2015).

Ainda, é importante enfatizar o índice cada vez mais elevado da violência contra a mulher na região Nordeste. De acordo com a pesquisa realizada pela Organização das Nações Unidas (ONU), em parceria com outras instituições, em 2016, aproximadamente $20 \%$ das mulheres dessa região sofreram algum tipo de violência (ONU mulheres, 2016).

Além da violência física contra a mulher, outros tipos podem ser destacados: a violência psicológica, a moral e a patrimonial. E pode ser classificada como doméstica e/ou institucional. No que se refere a violência doméstica, alvo deste estudo, de acordo com a Lei Maria da Penha, consiste em violências praticadas, na maioria das vezes, por parceiros ou familiares da pessoa, constituindo-se como uma violação dos direitos humanos no âmbito da unidade doméstica (Lei $n^{\circ} 11.340,2006$ ).

De acordo com Barbosa et al. (2014), essa violação geralmente causa estados emocionais de tristeza, insegurança e baixa autoestima, que, quando não são devidamente acolhidos e encaminhados, podem prejudicar o enfrentamento da violência, e até fomentar quadros psiquiátricos.

Dentro da literatura, a violência contra a mulher e as demandas de saúde mental ou sofrimento ético-político têm sido cada vez mais correlacionadas.
Por sofrimento ético-político, conceito postulado por Bader Sawaia em 1999, compreende-se como um fenômeno causado pela situação social da pessoa, que a coloca em uma posição de subalternidade e/ou inferioridade (Bertini, 2014).

Dillon et al. (2013), realizaram um levantamento de 75 artigos, entre 2006 e 2012, nos quais se evidencia essa relação entre a violência contra a mulher e o sofrimento ético-político. Além disso, já se torna representativa a quantidade de artigos que fundamentam essa correlação, posteriores aos anos de recorte da pesquisa de Dillon e colaboradores (Alves, 2018; Barbosa et al., 2014; Campos \& Zanello, 2016; Carneiro et al., 2017; Mota, 2017; Pedroza \& Zanello, 2016; Zanello et al., 2015).

Sabe-se que a violência doméstica atinge toda a família, principalmente os filhos, além de gerar a fragilização das relações sociais das mulheres decorrentes de seu isolamento (Conselho Federal de Psicologia [CFP], 2013). Apesar disso, os estudos citados anteriormente, não abordam as redes informais de cuidados das mulheres em situação de violência doméstica e em sofrimento ético-político, e é essa lacuna que que o presente estudo busca preencher.

Por redes informais de cuidado, compreendem-se as redes sociais primárias caracterizadas por vínculos estabelecidos nas relações de parentesco, família, amizade e vizinhança, constituídos na reciprocidade e na confiança. Considera-se os vínculos familiares, com vizinhos e instituições (como igreja e associações) como importantes, entre outras questões, para as situações de adoecimentos e demais dificuldades do cotidiano (Netto et al., 2017a).

Netto et al. (2017a) destacam o isolamento das mulheres de suas redes informais, em decorrência da situação de violência doméstica, já que os companheiros, muitas vezes, as questionam sobre suas relações sociais. E isso pode representar uma fragmentação do apoio social dessas mulheres e impactar no enfrentamento da violência. 
Além disso, compreende-se que as redes informais estão presentes no território das pessoas, e a noção de território não se reduz à área geográfica, pois está relacionado a uma dimensão simbólica e/ou cultural, bem como econômico-política (Monken et al., 2008. Nesse sentido, pensar em território é levar em consideração as pessoas, as instituições, as redes e os cenários construídos na vida comunitária (Gazignato \& Silva, 2014).

"É no território que se inscreve uma identidade social, uma prática social, a construção histórica e a identidade coletiva dos sujeitos sociais" (Dutra \& Oliveira, 2015, p. 534). Além disso, o território se constitui pela possibilidade de circular, e, nesse processo móvel, construir relações sociais e redes de cuidados informais (Gomes \& Merhy, 2014). Portanto, trabalhar no território significa utilizar os saberes, forças (potencialidades) e recursos da comunidade, que podem contribuir na discussão sobre as demandas e nas propostas de soluções coletivas, a fim de desencadear a construção de objetivos comuns no processo de cuidado (Dutra \& Oliveira, 2015).

Destaca-se, nessa perspectiva, que a inserção das equipes de saúde no território das pessoas e o contato com a rede informal, promove um processo de cuidado que estimula a autonomia e participação social dos usuários no cuidado em saúde (Eslabão et al., 2017).

Nesse sentido, ao levar em consideração a importância das redes informais no processo de cuidado, objetivou-se, neste estudo, investigar como se configuram as redes de cuidados informais das mulheres em situação de violência doméstica e que são atendidas por serviços de atenção especializada em saúde e assistência social, em um município do interior do Rio Grande do Norte. Essa proposta também buscou promover espaços de debates, a fim de contribuir para uma maior aproximação entre os dispositivos de saúde (redes formais) em questão e as redes informais das usuárias atendidas.

\section{Metodologia}

Este estudo está orientado pela perspectiva qualitativa de pesquisa, a fim de se abrir "à realidade social para melhor apreendê-la e compreendê-la" (Martins, 2004, p. 292). Além disso, a metodologia dessa pesquisa teve como referência a Análise Institucional, em uma perspectiva de pesquisa-intervenção e problematização das políticas instituídas no campo da saúde coletiva (L'Abbate, 2012; Lourau, 1975). A tarefa da Análise Institucional, nesse sentido, é descobrir/desvelar o não dito das instituições, a partir da problematização e do questionamento às instituições (Lourau, 2004). De acordo com Barbosa et al. (2014), trata-se de uma concepção teórico-metodológica de análise que parte da necessidade de identificar os analisadores, compreendidos como os acontecimentos que podem revelar as relações entre as lógicas instituídas (o que se mantém) e os processos instituintes (o que está em mudança).

Ainda, é importante destacar que esse estudo parte do princípio da pesquisa-intervenção. Isso significa dizer que a dimensão subjetiva do pesquisador e as situações vividas no campo são parte das fontes na produção do conhecimento. Em suma, a neutralidade científica é recusada dentro da pesquisa interventiva (Barbosa et al., 2014).

A pesquisa foi desenvolvida especificamente no Centro de Atenção Psicossocial II (CAPS II) e no Centro de Referência em Assistência Social (CREAS) de uma cidade do interior do Nordeste. O CAPS faz parte da proposta da reforma psiquiátrica, a fim de romper com a institucionalização e promover um espaço humanizado de cuidado às pessoas com demandas de saúde mental. Esta escolha se deu por esse serviço ter a responsabilidade de fornecer uma atenção contínua e integral, e em rede, às pessoas em sofrimento psíquico grave, sendo este o perfil ao qual esse estudo se endereça.

O CREAS, por sua vez, se constitui como um dispositivo de proteção/acolhimento de pessoas em situação de risco e/ou com direitos já violados, 
e mais especificamente, atende mulheres em situação de violência, público pelo qual esse estudo também se interessa.

Os participantes desta pesquisa consistiram em: mulheres atendidas pelo CAPS II e CREAS em situação de violência doméstica; profissionais que as acompanham; e a rede informal de cuidados (amigos, familiares, entre outros). As mulheres foram escolhidas a partir de discussões realizadas com os profissionais sobre quais usuárias poderiam ser entrevistadas, levando-se em consideração casos em que se identificaram histórico de violência doméstica.

Ao todo, foram realizadas seis rodas de conversas com os profissionais do serviço, entrevistas com quatro usuárias atendidas pelo serviço e com histórico de violência doméstica. Em uma das entrevistas, houve a participação da mãe de uma das usuárias, em função das dificuldades de fala da usuária em questão. E, a partir desses dados, foram produzidos ecomapas para uma melhor compreensão de como se organizavam as redes das entrevistadas.

Além disso, obteve-se 42 páginas digitalizadas de observações no diário de pesquisa utilizado durante o processo, que ocorreu entre agosto de 2018 e junho de 2020. O diário de pesquisa é uma ferramenta na qual se tem a acumulação do escrito, das experiências, reflexões e sentimentos, e, com o transcorrer do tempo, pode adquirir uma dimensão histórica, tornando-se um banco de dados (Hess, 2006). Assim, o diário é escrito no cotidiano, quando se vive ou se pensa, diferenciando-se da história de vida ou das memórias.

Em relação às entrevistas, do tipo não estruturadas, consistiram em conversas com as mulheres, familiares e profissionais, a fim de conhecer a história dessas usuárias, deixando que falassem livremente sobre isso. E, a partir desse relato, quando o diálogo permitia, se questionava acerca das redes formais e informais que haviam sido acionadas como fonte de cuidado.

Por fim, em relação aos ecomapas são ferramentas utilizadas para melhor compreender a or- ganização social e familiar das pessoas (Bergallo \& Nascimento, 2018). E, nesse sentido, foram utilizados com a finalidade de entender como se apresentam as relações formais e informais das usuárias entrevistadas.

Na proposta inicial da pesquisa, pretendia-se a realização de visitas domiciliares às usuárias entrevistadas, no entanto, em decorrência da doença causada pelo "novo coronavírus" (SARS-COV-2), ou COVID-19, não foi possível visitar todas as mulheres.

Após a submissão do projeto para apreciação do Comitê de Ética em Pesquisa da UFRN-FACISA (parecer $\mathrm{n}^{\circ} 3.015 .103$ ), e observadas as recomendações éticas previstas na resolução 510/16 do Conselho Nacional de Saúde, foram realizadas as rodas de conversa com os profissionais do CAPS II e do CREAS sobre a temática da violência doméstica, com o intuito também de fazer um levantamento de quais as mulheres que estavam dentro do perfil da proposta da pesquisa.

De maneira geral, as seis rodas de conversa realizadas se caracterizaram da seguinte forma: apresentação breve aos profissionais sobre a proposta da pesquisa-intervenção em questão; espaço de diálogo sobre o tema da violência doméstica; escolha das mulheres que poderiam ser entrevistadas; discussão sobre os resultados parciais obtidos a partir da inserção no serviço, e diálogo com os profissionais; apresentação final dos resultados do projeto como um todo, e espaço para discutir questões relacionadas às vivências das usuárias entrevistadas, as vivências das pesquisadoras e as percepções dos profissionais.

Após a escolha das usuárias, foi iniciado o contato com essas mulheres, os profissionais que as acompanham no serviço e pessoas próximas (como familiares e amigos). Para a realização desse processo, foi levada em consideração a disponibilidade do serviço e das usuárias em questão, a fim de não prejudicar em nenhum aspecto a atuação do CAPS ou deixar o ambiente desconfortável para as mulheres. É importante destacar que ao longo dos resultados e discussões as mulheres entrevistadas 
serão identificadas através de nomes fictícios, a fim de preservar suas identidades.

A partir das rodas de conversas e da transcrição das entrevistas, bem como dos demais instrumentos utilizados, foram destacados os analisadores que revelaram os processos instituídos e instituintes referentes a configuração das redes informais das mulheres atendidas pelo CAPS II e pelo CREAS.

\section{Resultados e Discussão}

As mulheres entrevistadas no CAPS II e no CREAS foram, respectivamente, Violeta, Margarida, Tulipa e Girassol (nomes fictícios), todas em situação de violência doméstica. A seguir serão apresentadas, resumidamente, as histórias dessas mulheres e a representação de suas redes formais e informais a partir de ecomapas.

\section{Violeta}

Violeta (figura 1) morava com seus pais em uma cidade da Paraíba, aos 14 anos, quando conheceu o seu ex-companheiro e deixou de estudar. Ele também passou a morar com a família de Violeta na mesma casa, e lá mesmo começaram as agressões, de acordo com o relato da mãe da usuária. A mãe de Violeta, após perceber que havia sido roubada pelo esposo da filha, o expulsou de casa, o que levou ao casal a morar em outro local. E nessa nova casa a violência se intensificou, sendo Violeta proibida de ver sua família. A mãe de Violeta buscou intervenção jurídica, e com o relato da filha, a justiça determinou uma medida protetiva que busca garantir uma distância mínima de 200 metros de seu ex-companheiro.

Esse relacionamento durou 12 anos e dele nasceram 2 filhos. O ex-companheiro ainda ameaça a vida de Violeta através de recados enviados por conhecidos, e possui uma relação conflituosa com os filhos. Atualmente, Violeta tem 35 anos, mora com os pais e seus filhos. Após a separação, se mudaram para uma cidade do interior do Nordeste. Violeta não trabalha e depende dos cuidados da mãe, principalmente no tratamento que realiza no CAPS. Já com o pai, estabelece pouca relação.
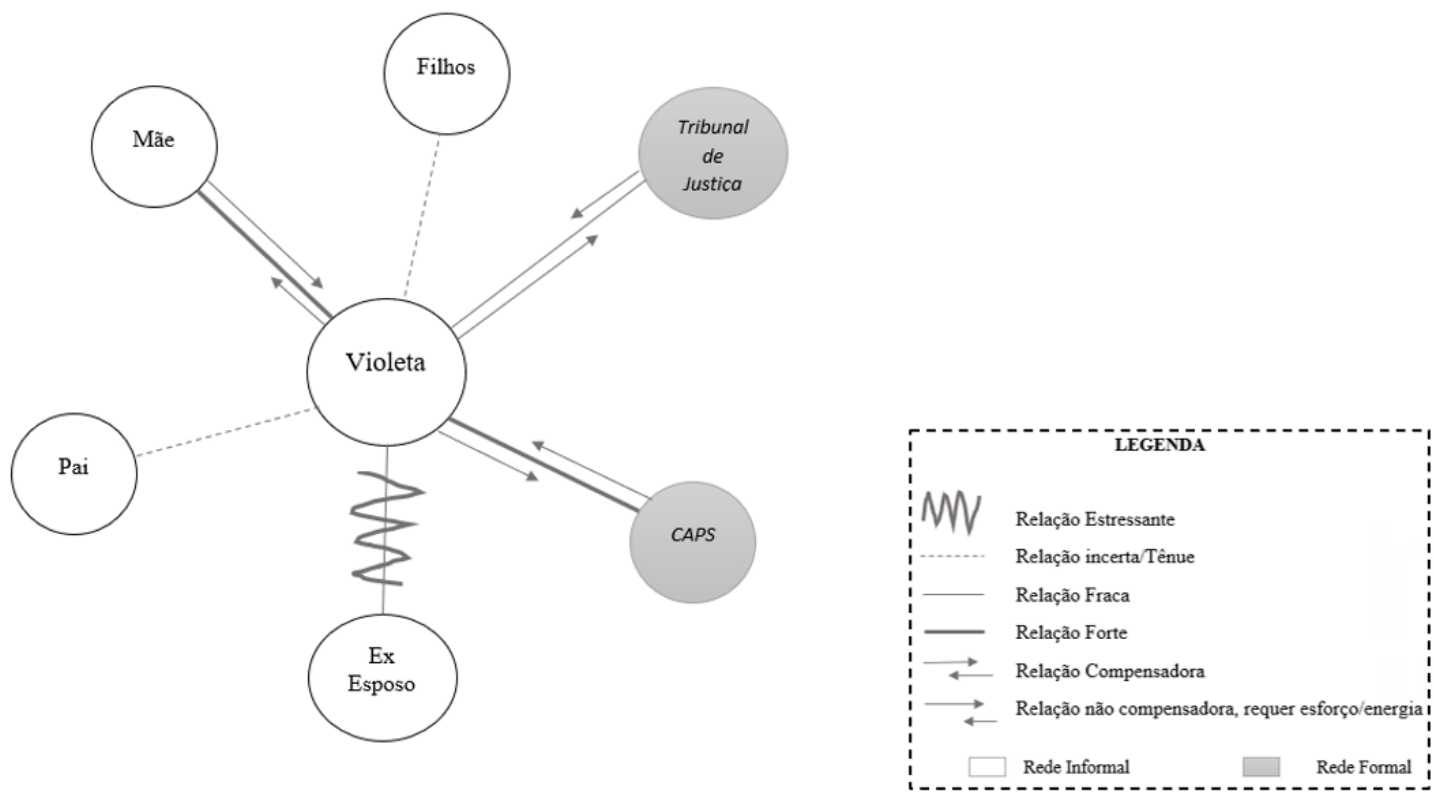

Figura 1. Configuração das redes da entrevistada 01, Violeta 


\section{Margarida}

Aos 13 anos de idade, Margarida (figura 2) foi expulsa de casa pela sua família por ter tido a sua primeira relação sexual. Isso a colocou em situação de rua, sendo acolhida por um homem no qual depositou "a confiança de dias melhores", como relata a usuária.

Margarida está nesse relacionamento desde então, e dele nasceram 3 filhos e ocorreu um aborto. Afirma que até 2 anos antes da entrevista, esse relacionamento foi marcado por violência e falta de apoio do ex-companheiro. No seu relato, destaca que o esposo e a família dele a tratam com desprezo, e que foi agredida por eles durante muitos anos. Dois anos antes da entrevista conheceu um grupo de dança, do qual seu esposo recusava que ela participasse. Sem aceitar a decisão do companheiro, Margarida passou a frequentar esse grupo. A partir disso, declarou que caso o esposo continuasse com a violência e com as privações, iria pedir a separação. Após isso, destaca que a relação entre eles se modificou e que, apesar de ainda não sentir apoio do companheiro, a violência física cessou, e aponta o cônjuge como uma figura de forte importância em sua vida.

Atualmente Margarida tem 40 anos e não trabalha. Tentou suicídio recentemente, e tem sido atendida pelo CAPS.

\section{Tulipa}

Ainda criança, Tulipa (figura 3) residiu na zona rural de sua cidade natal com seus familiares e frequentou pouco a escola. Aos 11 anos engravidou do primeiro filho, gravidez da qual não se recorda como aconteceu: "não me lembro de nada, eu era muito nova né!? De repente eu estava buchuda, só lembro eu com a barriga crescendo até ter o menino", afirmou.

Em busca de emprego, ainda adolescente, mudou-se para uma cidade de Minas Gerais, para trabalhar em um restaurante e na casa de uma conhecida da família. E foi com o filho dessa conhecida que estabeleceu um relacionamento. Segundo Tulipa, ele a agredia com chutes no início da relação. Diante dessa situação, com o apoio da sogra, Tulipa
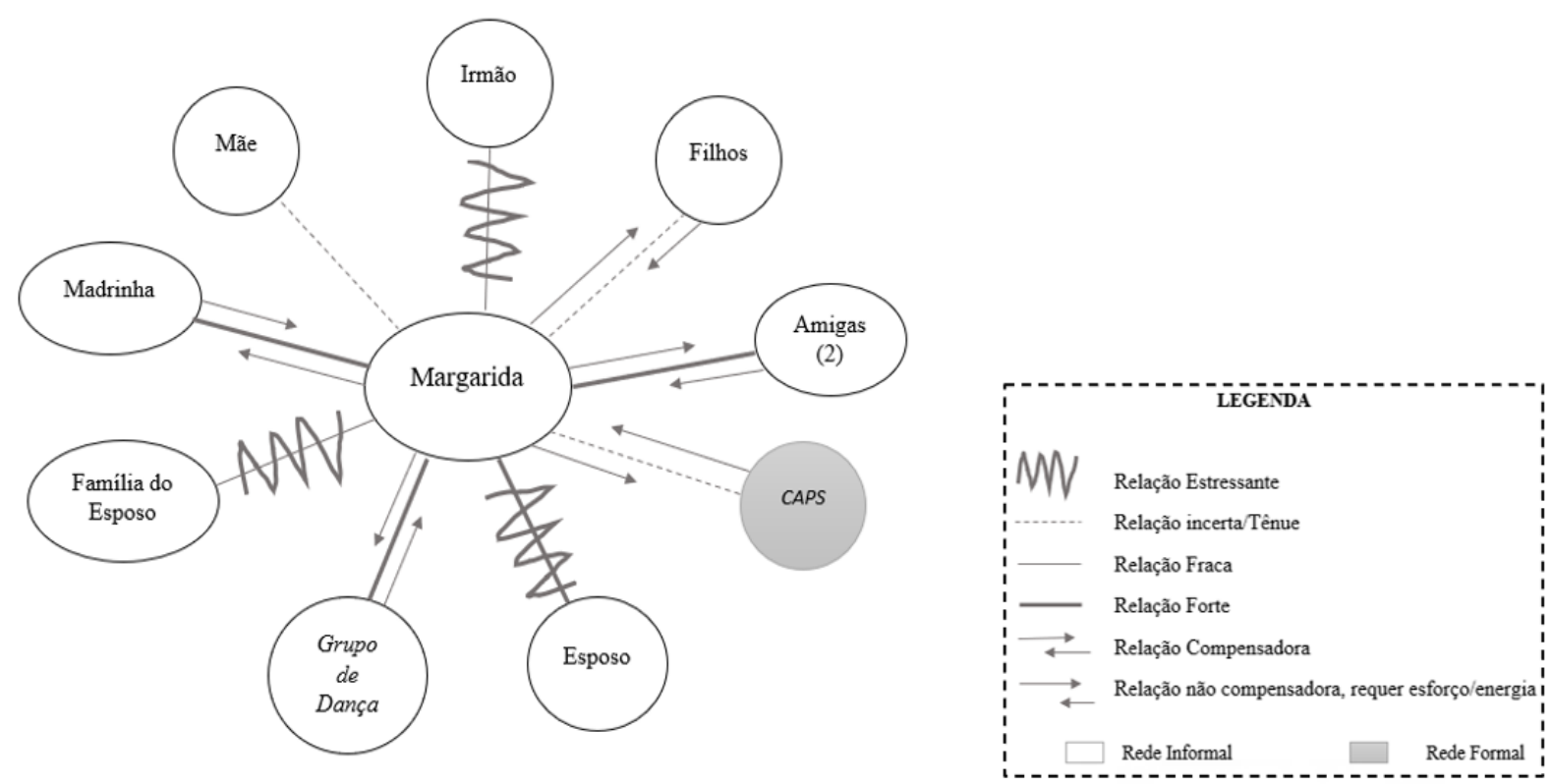

Figura 2. Configuração das redes da entrevistada 2, Margarida 
separou-se e mudou-se de cidade, onde começou outro relacionamento. Dessa relação nasceram 3 filhos e um forte vínculo com a sogra. Tulipa relatou que também esse companheiro a agrediu quando estava alcoolizado, o que a fez, após 5 anos, terminar o relacionamento. Seus filhos foram criados pela mãe desse ex-companheiro.

Ainda nessa cidade, com 18 anos, Tulipa iniciou um novo relacionamento, do qual nasceram 2 filhos, que também foram criados pela mãe desse companheiro. Juntos, Tulipa e o esposo se mudaram para a cidade natal dela e passaram a trabalhar em um bar, e esse período foi marcado pelo uso de álcool e outras drogas pelo casal, bem como de episódios recorrentes de violência. Aos 30 anos, Tulipa separou-se desse companheiro.

Ainda em sua cidade natal, começou um novo relacionamento, do qual nasceu 1 filho. Nesta relação, aconteceu situação semelhante à anterior: uso de álcool e outras drogas e episódios frequentes de violência. Durante esse relacionamento, a usuária relata que passou situação de violência extrema, exemplificada pelo corte de sua orelha pelo companheiro. Nesse período, ela também foi denunciada à justiça, em decorrência do uso de drogas junto ao filho, acusada de negligência. Foram 12 anos com esse companheiro até que ele foi assassinado em outra cidade, o que a fez também passar por dificuldades financeiras, sem condições para alimentar a si mesma e ao filho.

Atualmente tem 42 anos, e está em um novo relacionamento, no qual afirmou não existirem episódios de violência. Trabalha como faxineira quando surgem oportunidades, recebe o Bolsa Família (programa do governo), apoio financeiro de amigos, e tem sido acompanhada pela equipe do CREAS.

\section{Girassol}

Girassol (figura 4) cresceu na zona rural e possui ensino fundamental. Tinha 10 anos quando seu pai faleceu, e foi acolhida por uma amiga da família na cidade vizinha, onde também começou a trabalhar como faxineira. Nesse período teve relacionamentos dos quais nasceram 3 filhas, e estas foram criadas pelas irmãs de Girassol, já que ela não tinha condições de criá-las. Irmãs essas com as quais não mantém mais vínculos.
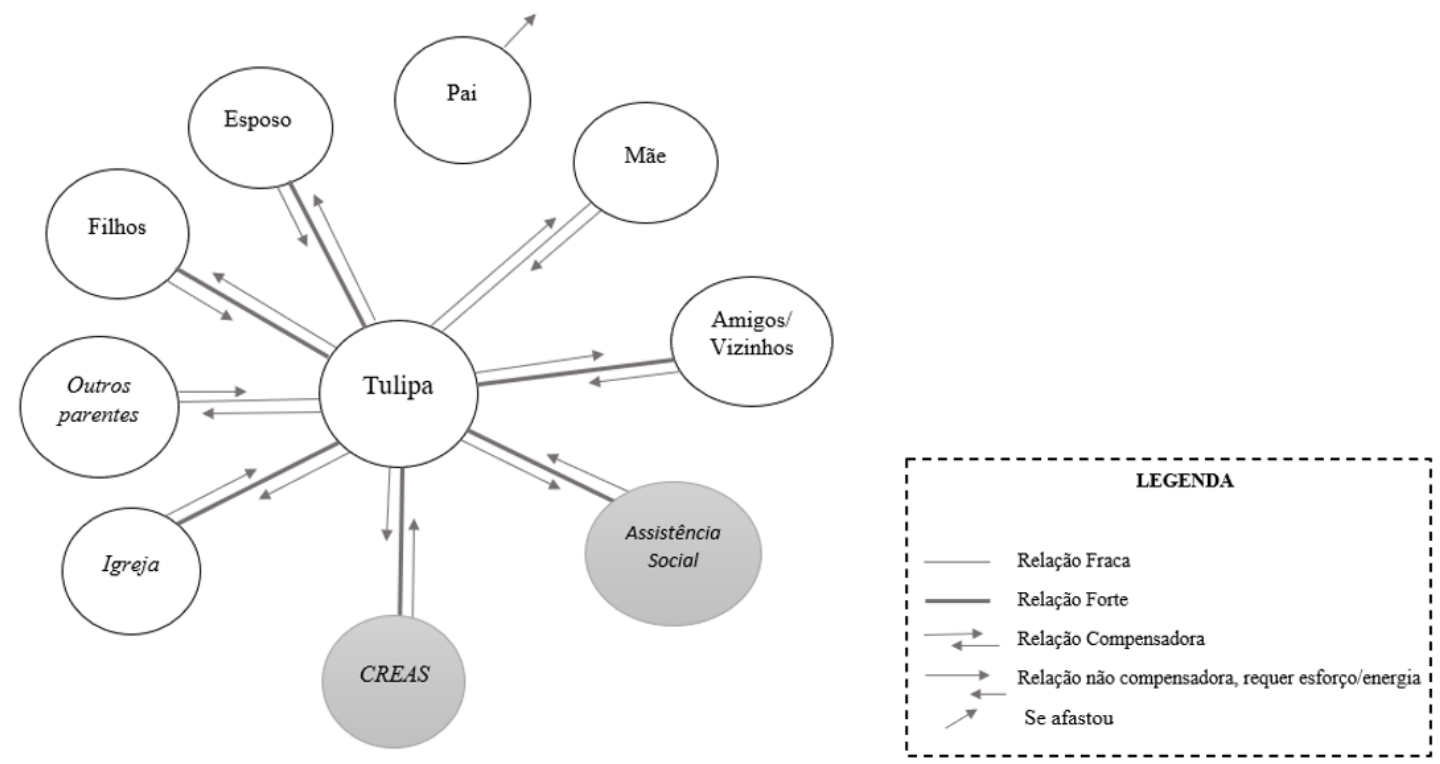

Figura 3. Configuração das redes da entrevistada 3, Tulipa 
Ainda nessa cidade, conheceu seu último companheiro, e desse relacionamento nasceram 3 filhas. Anos depois, Girassol passou a trabalhar com costura e se mudou para a sua cidade natal. De acordo com o relato de Girassol, os episódios de violência não demoraram para acontecer. Apesar de o cônjuge se mostrar companheiro, logo os episódios de violência começaram através de empurrões e gritos, principalmente quando ele estava embriagado. Inclusive, houve um episódio em que ele ateou fogo em sua casa.

Foram 15 anos de relacionamento e violência destacados pela usuária, que recentemente se separou. Atualmente, Girassol tem 39 anos, trabalha com faxinas, recebe o Bolsa Família (programa do governo), e é acompanhada pela equipe do CREAS.

A partir das entrevistas com as quatro mulheres e dos dados obtidos pelos outros instrumentos utilizados, foram identificados três analisadores: da fragmentação à reconstrução das redes informais no contexto de violência doméstica; relação entre a rede formal e informal; redes quentes e vivas, redes transformadoras.

\section{Analisador 01: da fragmentação à reconstrução das redes informais no contexto de violência doméstica}

A partir da análise das redes informais das usuárias entrevistadas, compreende-se que todas elas apresentam uma rede social fragmentada em função dos episódios de violência doméstica, e que outros vínculos foram se construindo no sentido do fortalecimento das mulheres para o enfrentamento da situação de violência.

A exemplo disso, a usuária Tulipa (figura 3) apresentou em seu relato que sua família não estava de acordo com a situação de violência com a qual ela lidava, e, por essa razão, poucos ou nenhum dos familiares mantinham contato. Compreende-se, nesse sentido, que, diante da situação de violência doméstica, alguns laços se modificaram ou foram rompidos. E, consequentemente, Tulipa não recebe apoio de sua família.

Ela disse que a maioria deles [familiares] não concorda com o seu casamento, pois sabem dos episódios de violência que ela vivencia e se afastam. [...] relata que possui familiares, inclusive
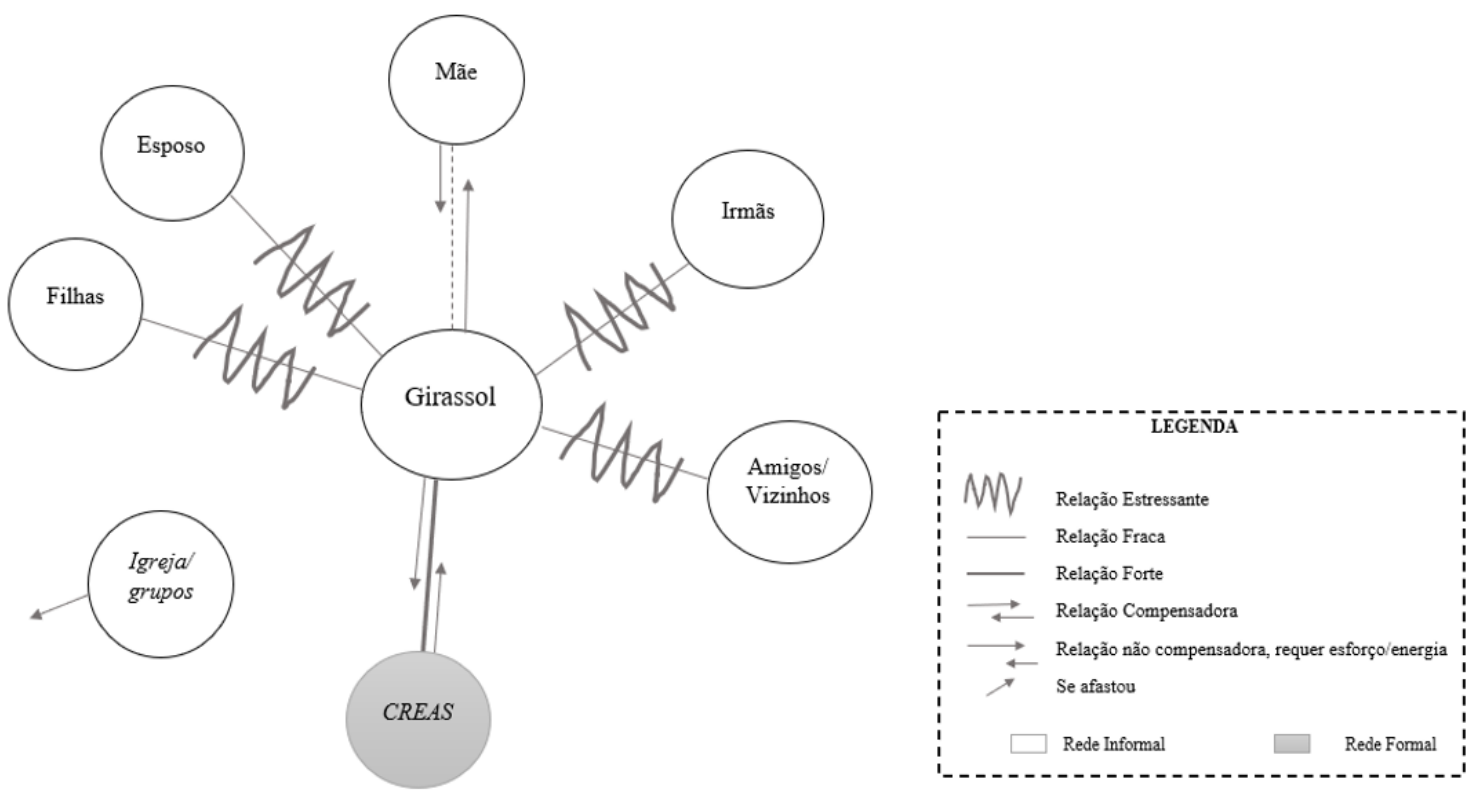

Figura 4. Configuração das redes da Entrevistada 4, Girassol 
sua mãe, morando em outra cidade, mas que não possui contato com quase ninguém, pois a família se volta contra o seu relacionamento (Diário de Pesquisa, 11 de junho de 2019).

Nas histórias trazidas pelas usuárias, as relações com os filhos se tornaram frágeis a partir da experiência dos históricos de violência e de vulnerabilidade vivenciados: Tulipa e Girassol doaram os filhos, Margarida sofreu um aborto e Violeta possui uma relação distante com os filhos.

Além disso, duas usuárias desenvolveram relações conflituosas com as mães, e uma delas, com as irmãs. A primeira se refere à Margarida, que relatou possuir pouco vínculo com a mãe, em decorrência da situação de violência doméstica que vivenciou quando adolescente ainda na casa dos pais. A outra é Girassol, as suas filhas foram criadas por irmãs que conheciam a situação de violência em que estava inserida e não concordavam. Nesse sentido, mediante o contexto de violência doméstica vivenciado, essas duas usuárias tiveram alguns dos seus vínculos familiares fragmentados e/ou rompidos.

Dutra et al. (2013) apontam em seu estudo essa transformação nas redes sociais das mulheres a partir da situação de violência praticada por seus cônjuges. Além disso, estes autores indicam que essa fragilização pode prejudicar também o acesso das mulheres às redes formais de cuidado, e pode tornar ainda mais tardio o enfrentamento dessa situação.

Três das quatro mulheres entrevistadas (figura 1, 2 e 4) indicaram que possuem suporte de cuidado de pelo menos uma pessoa inserida no seio familiar. Resultado semelhante foi encontrado por Netto et al. (2017b), com destaque no suporte material e/ou emocional. Nesse sentido, o apoio familiar, apesar de fragilizado em algumas situações, se mantém instituído como uma rede informal, e é um suporte de fundamental importância no processo de cuidado da mulher em situação de violência e com demandas de saúde mental. Compreende-se que os familiares são considerados, na maioria das vezes, como protetores (Santi et al., 2010), fonte de apoio aos usuários (Pelgoraro \& Caldana, 2008), e compõem o contexto sociocultural da pessoa que demanda cuidado.

Ademais, essas três entrevistadas, Violeta, Margarida e Tulipa, apontaram que recebem apoio, principalmente, de outras mulheres: mãe, madrinha e amigas próximas. Esse cuidado se refere principalmente à escuta da usuária, e cuidados diários (como no caso de Violeta), que recebe apoio integral da mãe no cuidado pessoal. Isso reforça a ideia de que à figura feminina é delegado esse papel de cuidadora do lar e das pessoas ao redor que precisam de ajuda (Kantorski et al., 2019), e que comumente são as mulheres que prestam cuidados às pessoas usuárias de serviços de saúde mental (Pelgoraro \& Caldana, 2008).

Sobres as redes comunitárias, é importante frisar ainda a importância de um grupo de dança na comunidade para Margarida no seu fortalecimento para o enfrentamento da violência. Ela destaca que, a partir da escolha de participar desse grupo de dança, conseguiu conversar com o esposo sobre a situação de violência vivenciada e expressar sua decisão de não permanecer no relacionamento caso não ocorresse mudança.

Além desse caso, há a importância, destacada por Tulipa, da participação de amigas/vizinhas e a igreja como mantenedoras desse cuidado. Segundo Santi et al. (2010), diante da importância relacionada à família e amigos, estes podem ser, à princípio, o primeiro meio de proteção que as mulheres buscam quando em situação de violência. Além disso, a participação em grupos comunitários (como os religiosos) podem contribuir na integração com outras pessoas, e, dentre outras questões, na ampliação da rede social das mulheres (Biella, 2005).

Por outro lado, Netto et al. (2017b) apontam resultado distinto no seu estudo, uma vez que as usuárias relataram não frequentar a igreja por receio de serem julgadas pela decisão de divórcio, a partir da situação de violência doméstica. Nesse 
sentido, é importante destacar que os grupos também podem reforçar a culpabilização da mulher pela violência, e, consequentemente, fragmentar a rede de enfrentamento.

Dutra et al. (2013) reforçam a importância do apoio social no enfrentamento da violência. Por isso, torna-se essencial no âmbito das políticas públicas de proteção às mulheres garantir um trabalho junto à redes informais, para tensionar as relações instituídas de violências contra às mulheres e meninas em seus contextos sociais, com o reconhecimento da importância dessas redes.

\section{Analisador 02: relação entre a rede formal e informal}

A rede informal por si só não é suficiente para suprir as demandas das mulheres em situação de violência doméstica e sofrimento ético-político, o que leva à chegada das mulheres às redes formais de cuidado, como os serviços oferecidos no âmbito da assistência social e da saúde mental. No processo de produção dos dados, notou-se que as mulheres entrevistadas recorreram ou foram encaminhadas ao CAPS II e/ou ao CREAS mediante as situações de violências e/ou efeitos dela.

No entanto, foi observada uma dificuldade que se mantém instituída no cuidado em saúde mental, principalmente no que se refere às mulheres em situação de violência doméstica: a desarticulação dos serviços com o território de vida das usuárias. Ocorre que, na maioria das vezes, as usuárias do CAPS II relatam a situação de violência apenas para psicóloga, que já trabalhou em serviços especializados na assistência social com essa demanda. E, mediante a ausência que encontramos, no início da pesquisa, de discussão dos casos dentro do serviço, a fragmentação do cuidado continua instituída, e não são acionados outros dispositivos das redes formais e informais que possam contribuir no cuidado integral dessas mulheres, o que pode reforçar a patologização das situações de violência.
No CAPS II, notou-se que as usuárias em situações de violência são acolhidas dentro dos muros do serviço, e sua família é acolhida também nesse espaço. Nesse serviço não têm sido realizadas visitas domiciliares, ou mesmo a articulação com a Atenção Básica, o que indica a ausência de trabalho com as redes territoriais nas quais as usuárias se inserem.

É perceptível o quanto a rede formal se articu-

la de forma limitada à rede informal de cuidado.

Essa relação se resume a um contato breve dentro

do próprio serviço entre um profissional e algum membro da família ou amigo que veio como acompanhante do usuário. Não há um contato direto com o território das pessoas. Não existem visitas que busquem conhecer o contexto informal dos usuários. Assim, a rede formal atua fechada em si mesma, e a rede informal da mesma maneira.

(Diário de Pesquisa, 31 de maio de 2019)

Dessa maneira, percebemos que esse tipo de cuidado termina por reproduzir uma lógica de patologização do sofrimento dessas mulheres. Nesse processo de construção do cuidado e acolhimento das mulheres em situação de violência, é possível fomentar ainda mais o processo instituído de invisibilização das relações entre sofrimento psíquico e as violências vivenciadas pelas mulheres, ou fazer resistência a isso.

Para Guedes et al. (2009), existem três aspectos que produzem e contribuem na invisibilização dos efeitos da violência na saúde física e psicológica das mulheres: a ausência de denúncia pela mulher acerca da violência, apenas apresentando queixas sintomáticas aos serviços; formação fragmentada dos profissionais, ainda pautada em um modelo tradicional; e a maneira pela qual as identidades de gênero foram construídas, uma vez que à mulher são direcionados estereótipos de submissão e obediência.

Por outro lado, a partir do CREAS, evidenciou-se a potência de trabalhar com visitas domiciliares e cuidado domiciliar quando se trata das questões de violência doméstica. Ao longo das rodas de conversas, observou-se a situação de Girassol, que 
se negava até então a separar-se do marido, que era o agressor, e receber o aluguel social. Nas visitas domiciliares para entrevista da usuária, o CREAS retomou o contato com a mulher e percebeu a importância da continuidade do seu atendimento e de suas filhas. Nesse processo de retomada de vínculo e acolhimento por meio de visitas domiciliares, a usuária se decidiu separar do marido.

Assim, a visita domiciliar é uma estratégia de acompanhamento psicossocial orientada para o território, que permite uma melhor visualização da realidade do cotidiano dessas mulheres, principalmente no que se refere à compreensão dos vínculos familiares. Além disso, é possível perceber as potencialidades e demandas da família, e contribuir no fortalecimento desses vínculos (CFP, 2013). Nesse sentido, a execução das visitas preconiza uma assistência em saúde mais integral e mais inserida no cotidiano das pessoas, sem desrespeito à sua privacidade (Dutra \& Oliveira, 2015).

Compreende-se ainda a importância do resgate do contexto e da vida cotidiana da pessoa que busca o serviço, a fim de identificar e não silenciar questões para além do que é dito nos sintomas (Zanello \& Silva, 2012). Ainda, a articulação entre essas redes requer um trabalho conjunto, em que, principalmente os profissionais de saúde e assistência social busquem conhecer o território e a rede informal dessas mulheres, para, relacionados, construir o cuidado (Kemper et al., 2015).

\section{Analisador 03: redes quentes e vivas, redes transformadoras}

Quando se analisa mais especificamente as rodas de conversas, ao comparar as primeiras e a última roda realizadas com os profissionais do CAPS II, notou-se uma possível transformação de olhar desses profissionais em relação à situação de violência vivenciada pelas usuárias atendidas pelo serviço. Esse processo pode ter contribuído para impulsionar a construção de uma rede mais ativa, ou seja, uma rede quente, viva e, portanto, transformadora (Ferla et al., 2015).

Nas primeiras rodas de conversas quando se apontava a questão da violência contra mulher, os profissionais só se remetiam às experiências vivenciadas em suas redes mais próximas, familiares e/ ou de amizades. Nesse sentido, foi perceptível o não reconhecimento e, portanto, a possível invisibilidade das violências no serviço, o que pode evidenciar a naturalização da violência doméstica vivenciada pelas usuárias por parte dos profissionais. E aqui é importante destacar, em primeiro lugar, que a maior parte das profissionais dos serviços em questão, são mulheres cisgêneros.

Já na última roda de conversa, o olhar se voltava para uma lógica de existência de um sistema de opressão socialmente construído sobre as mulheres.

[...] em comparação ao início do processo de pesquisa, as profissionais se referiram de forma diferente à questão da violência doméstica.

Dessa vez, a percepção se voltava muito mais para uma realidade, de fato, opressora, na qual as mulheres estão inseridas. E esse olhar é parte importante para que o cuidado seja ofertado de forma mais acolhedora. (Diário de Pesquisa, 30 de junho de 2020)

Nesse sentido, como movimento instituinte no processo de enfrentamento da violência contra a mulher, ao longo das rodas de conversas, foi possível notar a construção de um processo de sororidade das profissionais do serviço em relação às mulheres atendidas.

O questionamento das violências de gênero contra as diferentes mulheres se torna importante na perspectiva de desnaturalização do sexismo que constitui a sociedade (Hooks, 2020). Para tanto, a noção de sororidade ganha importância na medida em que há um reconhecimento mútuo de que as mulheres são oprimidas e sofrem violência de diferentes maneiras de acordo com diversos marcadores, dentre eles classe e raça. Aqui utiliza-se o termo a partir da consideração de que existem diferenças entre as mulheres, seja por cor, classe 
econômica ou outro aspecto, que reiteram que não se pretende propor uma "igualdade utópica" a partir desse conceito (Silva, 2016). Ou seja, a sororidade como processo de construção de solidariedade entre mulheres compreendendo as suas diferentes necessidades (Hooks, 2020).

É válido destacar que os profissionais de saúde fazem parte de uma rede, e a atuação não se resume ao que se realiza dentro do serviço, uma vez que uma noção ampliada de rede extrapola a organização dos serviços e se implica com os vínculos do território das pessoas (Righi et al., 2014). É necessária a inserção no território das pessoas, superando as paredes institucionais, e construindo parcerias com dispositivos informais de cuidado que fazem parte da história concreta e singular dos indivíduos (Silva \& Pinho, 2015) - ou até mesmo contribuir na produção dessas redes. Sobre isso, Righi et al. (2014) apontam a importância da construção de parcerias não apenas entre os serviços, mas principalmente a relação entre serviço e usuários.

Um ponto de destaque na realização dessa última roda de conversa, foi o fato de ter sido realizada simultaneamente com os profissionais do CAPS e CREAS. Esse tipo de encontro não acontece com frequência, de acordo com o que eles relataram, e essa possibilidade de aproximação pode ter suscitado uma possibilidade de essas redes se integrarem mais fortemente no processo de oferta do cuidado. Eles mesmos ressaltaram a importância dessa integração. (Diário de Pesquisa, 30 de junho de 2020)

Compreende-se que para que se possa "fazer redes", é imprescindível que os trabalhadores não se prendam em demasiado "ao saber/fazer individual" e sim que consigam dar enfoque àquilo a que buscam promover mudança (Righi et al., 2014 , p. 62). No entanto, isso se estabelece como um desafio, principalmente quando se considera o processo formativo desses profissionais, que muitas vezes limita essas possibilidades; a Educação Permanente é uma forma que busca suprir essas fragilidades (Ferla et al., 2015).
Nesta perspectiva, é válido apontar que essa pesquisa se inseriu como potência nessa noção de Educação Permanente, contribuindo para uma construção coletiva de conhecimentos e afetações em relação às nuances atreladas ao contexto de violência contra as mulheres. Em consonância, para Ferla et al. (2015):

As organizações e os grupos de trabalho do sistema local e os atores da universidade, ao estabelecerem relações de aprendizagem recíproca, enlaçam uma rede de aprendizagens para as questões do cotidiano, de aprendizagem significativa. Saberes de lado a lado conectam essa rede. Ou seja, trata-se de analisar permanentemente o cotidiano do trabalho, destacar situações que mobilizam seus atores, construir teias de saberes locais, desenvolver tecnologias e iniciativas para superar essas questões, monitorá-las e avaliá-las, mas, também e predominantemente, produzir e compartilhar conhecimentos a partir dessas experimentações. As redes de ensino e sistema local precisam ser redes de conhecimentos, para consolidar aprendizagens e para se renovar. Falamos aqui de uma rede quente, no sentido de intervenções produtoras da capacidade de "operar em rede" e de "produzir experimentações" capazes de transformar o cotidiano do serviço e da formação. (pp.17-18)

\section{Considerações Finais}

A partir da realização dessa pesquisa foi possível compreender o quanto as mulheres em situação de violência, apesar de terem alcançado avanços no que concerne às leis de proteção e garantia de direitos, ainda sofrem com a fragmentação de suas redes informais de cuidado mediante situações de violências, e da necessidade de trabalhar essas temáticas nos serviços de saúde e assistência.

As redes informais das usuárias entrevistadas apresentaram especificidades que repercutem no 
processo de enfrentamento da violência vivenciado por elas, e reitera a importância dessa rede na construção do cuidado.

Além disso, é necessário que a rede de cuidado formal busque a integração com a rede informal dos usuários do serviço, para conhecer o território dessas pessoas e possibilitar a corresponsabilidade do cuidado, e para romper com a desarticulação instituída entre essas duas redes - produzindo redes quentes e vivas.

Ademais, a naturalização, invisibilização e silenciamento da violência também são dificuldades que se mantêm instituídas, e fundamentam-se nas desigualdades de gênero que colocam o feminino e as mulheres em uma condição de inferioridade em diversas áreas da vida.

Sobre a realização dessa pesquisa, compreende-se que a utilização de ecomapas como instrumento contribuiu para a análise e reflexão sobre os dados das redes informais das usuárias entrevistadas, sendo uma importante ferramenta para este estudo.

Ainda, essa proposta pode ter contribuído para que os profissionais pensassem ou repensassem sobre a questão da violência doméstica, retirando essa temática da dimensão do não dito. Além de ter potencializado o trabalho no âmbito do território tanto do CAPS quando do CREAS.

Por fim, destaca-se como limitações para essa pesquisa, entre outras questões, a dificuldade de acesso à rede informal das usuárias, já que não foi possível a realização de todas as visitas domiciliares, em decorrência da incidência da COVID-19, o que prejudicou a possibilidade de aprofundar a discussão sobre essa rede. Nesse sentido, como sugestão para pesquisas futuras, indica-se a realização dessas visitas.

\section{Referências}

Alves, M. (2018). Interfaces entre gênero e saúde mental abordadas por estudos qualitativos das ciências sociais e humanas: foco nas experiên- cias subjetivas. Revista Gênero, 18(2), 155-177. https://doi.org/10.22409/rg.v18i2.1149

Barbosa, L. B., Dimenstein, M., \& Leite, J. F. (2014). Mulheres, violência e atenção em saúde mental: questões para (re) pensar o acolhimento no cotidiano dos serviços. Avances en Psicología Latinoamericana, 32(2), 309-320. https://dx. doi.org/10.12804/apl32.2.2014.09

Bergallo, R., \& Nascimento, A. C. T. M. (2018). Ecomapa como instrumento na atenção primária à saúde. Revista PEBMED, 38-42. https://d335luupugsy2. cloudfront.net/cms/files/20941/1523281034Revista_-_1_edio.pdf

Bertini, F. M. A. (2014). Sofrimento ético-político: uma análise do estado da arte. Psicologia \& Sociedade, 26(2), 60-69. https://doi.org/10.1590/ S0102-71822014000600007

Biella, J. L. (2005). Mulheres em situação de violência-políticas públicas, processo de empoderamento e a intervenção do assistente social [Trabalho de conclusão de curso, Universidade Federal de Santa Catarina]. http://tcc.bu.ufsc. br/Ssocial286678.pdf

Campos, I. O., \& Zanello, V. (2016). Saúde mental e gênero: o sofrimento psíquico e a invisibilidade das violências. Revista de Antropologia, (48), 105-118. https://periodicos.ufrn.br/vivencia/ article/view/11505/8096

Carneiro, A. C., Murmel, J. G., \& Werner, R. (2017, 28-30 de junho). Relações de gênero e saúde mental: a marginalização da mulher com transtorno mental [Resumo expandido]. Anais do $3^{\circ}$ Fórum de Direitos Humanos e Saúde Mental, Florianópolis, SC, Brasil. http://www. direitoshumanos2017.abrasme.org.br/resources/anais/8/1489545418_ARQUIVO_Artigoabrasme.pdf

Conselho Federal de Psicologia [CFP]. (2013). Referências técnicas para prática de psicólogas(os) no Centro de Referência Especializado da Assistência Social. CFP.

Dillon, G., Hussain, R., Loxton, D., \& Rahman, S. (2013). Mental and physical health and inti- 
mate partner violence against women: A review of literature. International Journal of Family Medicine, Artigo 313909. https://doi. org $/ 10.1155 / 2013 / 313909$

Dutra, M. L, Prates, P. L., Nakamura, E., \& Villela, W. V. (2013). A configuração da rede social de mulheres em situação de violência doméstica. Ciência \& Saúde Coletiva, 18(5), 1293-1304. https://www.scielo.br/pdf/csc/v18n5/14.pdf

Dutra, V. F. D., \& Oliveira, R. M. P. (2015). Revisão integrativa: as práticas territoriais de cuidado em saúde mental. Aquichan, 15(4), 529540. http://www.scielo.org.co/pdf/aqui/v15n4/ v15n4a08.pdf

Eslabão, A. D., Coimba, V. C. C., Kantorski, L. P., Pinho, L. B., \& Santos, E. O. (2017). Rede de cuidado em saúde mental: visão dos coordenadores da estratégia saúde da família. Revista Gaúcha de Enfermagem, 38(1), 1-8. https://doi. org/10.1590/1983-1447.2017.01.60973

Ferla, A. A., Rocha, C. M. F., Dias, M. T. G, \& Santos, L. M. (2015). Redes vivas de educação e saúde e a integração universidade e sistema local de saúde: saberes locais e múltiplas saúdes como capacidade profissional e como atributo das redes de atenção. In A. A. Ferla, C. M. F. Rocha, M. T. G. Dias \& L. M. Santos (Orgs.), Redes vivas de educação e saúde: relatos e vivências da integração universidade e sistema de saúde (pp. 11-23). Editora Rede Unida.

Gazignato, E. C. S., \& Silva, C. R. C. (2014). Saúde mental na atenção básica: o trabalho em rede e o matriciamento em saúde mental na Estratégia de Saúde da Família. Saúde em Debate, 38(101), 296-304. http://dx.doi. org/10.5935/0103-1104.20140027

Gomes, M. P. C., \& Merhy, E. E. (2014). Pesquisadores IN-MUNDO: um estudo da produção do acesso e barreira em saúde mental (1 ed.). Rede UNIDA.

Guedes, R. N., Silva, A. T. M. C., \& Fonseca, R. M. G. S. (2009). A violência de gênero e o processo saúde-doença das mulheres. Escola Anna Nery,
13(3), 625-631. https://doi.org/10.1590/S141481452009000300024

Hess, R. (2006). Momento do diário e diário dos momentos. In E.C. Souza \& M. H. M. B. Abrahão (Orgs.), Tempos, narrativas e ficções: a invenção de si. EDIPUCRS.

Hooks, B. (2020). O feminismo é para todo mundo: políticas arrebatadoras (10 ed.). Rosa dos Tempos.

Instituto de Pesquisa Econômica Aplicada [IPEA]. (2020). Atlas da Violência de 2020. IPEA. https:// www.ipea.gov.br/portal/index.php?option=com_content\&view $=$ article\&id $=36488 \&$ Ite$\operatorname{mid}=432$

Kantorski, L. P., Jardim, V. M. R., Treichel, C. A. S., Andrade, A. P. M., Silva, M. S. S. J., \& Coimbra, V. C. C. (2019). Gênero como marcador das relações de cuidado informal em saúde mental. Cadernos Saúde Coletiva, 27(1), 60-66. https:// doi.org/10.1590/1414-462X201900010071

Kemper, M. L. C., Martins, J. P. A., Monteiro, S. F. S., Pinto, T. S., \& Walter, F. R. (2015). Integralidade e redes de cuidado: uma experiência do PET-Saúde/Rede de Atenção Psicossocial. Interface-Comunicação, Saúde, Educação, 19(1), 995-1003. https://doi.org/10.1590/180757622014.1061

L'Abbate, S. (2012). Análise Institucional e Intervenção: breve referência à gênese social e histórica de uma articulação e sua aplicação na Saúde Coletiva. Mnemosine, 8(1), 194-219. https://www.e-publicacoes.uerj.br/index.php/ mnemosine/article/view/41580/28849

Lei n. 11.340 de 2006. Lei Maria da Penha, cria mecanismos para coibir a violência doméstica e familiar contra a mulher. 07 de agosto de 2006. D.O.U de 08/08/2006, pág. $\mathrm{N}^{\mathrm{o}} 1$.

Lourau, R. (1975). Análise institucional. Vozes.

Lourau, R. (2004). Objeto e método na Análise Institucional. In S. Altoé \& R. Lourau (Orgs.), Analista Institucional em tempo integral (pp. 66-88). Hucitec.

Martins, H. H. T. S. (2004). Metodologia qualitativa de pesquisa. Educação e Pesquisa, 
30(2), 289-300. https://doi.org/10.1590/S151797022004000200007

Monken, M., Peiter, P., Barcellos, C., Rojas, L. I., Navarro, M. B. M. A., Gondim, G., \& Gracie, R. (2008). O território na saúde: construindo referências para análises em saúde e ambiente. In A. C. Miranda, C. Barcellos, J. C. Moreira \& M. Monken (Orgs.), Território, ambiente e saúde (pp. 23-42). Editora Fiocruz.

Mota, M. L. (2017). Violência contra as mulheres e saúde mental: silenciamentos e invisibilidades do sofrimento de usuárias da atenção primária à saúde em Recife [Dissertação de mestrado, Universidade Federal de Pernambuco]. https:// repositorio.ufpe.br/handle/123456789/25471

Netto, L. A., Moura, M. A. V., Araujo, C. L. F., Souza, M. H. N., \& Silva, G. F. (2017b). As Redes Sociais de Apoio às Mulheres em Situação de Violência pelo Parceiro Íntimo. Texto \& Contexto - Enfermagem, 26(2), 1-11. http://dx.doi. org/10.1590/0104-07072017007120015

Netto, L. A., Moura, M. A. V., Queiroz, A. B. A, Leite, F. M. C., \& Silva, G. F. (2017a). Isolamento de mulheres em situação de violência pelo parceiro íntimo: uma condição em redes sociais. Escola Anna Nery, 21(1), 1-8. https:// doi.org/10.5935/1414-8145.20170007

ONU Mulheres Brasil. (2016). Pesquisa de Condições Socioeconômicas e Violência Doméstica e Familiar contra a Mulher: Relatório Executivo I - Primeira Onda-2016. ONU. https://www.onumulheres.org.br/wpcontent/uploads/2017/11/ violencia_domestica_geracoes_out_17.pdf

Pasinato, W. (2015). Oito anos de Lei Maria da Penha: Entre avanços, obstáculos e desafios. Revista Estudos Feministas, 23(2), 533-545. https:// doi.org/10.1590/0104-026X2015v23n2p533
Pedrosa, M., \& Zanello, V. (2016). (In)visibilidade da violência contra as mulheres na saúde mental. Psicologia: Teoria e Pesquisa, 32, 01-08. https://doi.org/10.1590/0102-3772e32ne214

Pegoraro, R. F., \& Caldana, R. H. L. (2008). Mulheres, loucura e cuidado: a condição da mulher na provisão e demanda por cuidados em saúde mental. Saúde e Sociedade, 17(2), 82-94. https://www.scielo.br/pdf/sausoc/v17n2/09.pdf

Righi, L. B., Rohde L. S. P., Baibich, M. E., Macharelli, A. A., \& Robinson, P. G. (2014). Apoio para a produção de redes de (em) saúde: efeitos de percursos formativos em humanização da atenção e gestão do sus. Saúde \& Transformação Social, 5(2), 59-68. http://pepsic. bvsalud.org/scielo.php?script=sci_arttext\&pi$\mathrm{d}=\mathrm{S} 2178-70852014000200008$

Santi, L. N., Nakano, A. M. S., \& Lettiere, A. (2010). Percepção de Mulheres em Situação de Violência sobre o Suporte e Apoio Recebido em seu Contexto Social. Texto \& Contexto, Enfermagem, 19(3), 417-24. https://www.scielo.br/pdf/ tce/v19n3/a02v19n3

Silva, A. B., \& Pinho, L. B. (2015). Território e saúde mental: contribuições conceituais da geografia para o campo psicossocial. Revista Enfermagem UERJ, 23(3), 420-424. http://dx.doi. org/10.12957/reuerj.2015.10091

Zanello, V., Fiuza, G., \& Costa, H. S. (2015). Saúde mental e gênero: facetas gendradas do sofrimento psíquico. Fractal: Revista de Psicologia, 27(3), 238-246. https://doi.org/10.1590/1984-0292/1483

Zanello, V., \& Silva, R. M. (2012). Saúde mental, gênero e violência estrutural. Revista Bioética, 22(2), 267-279. https://revistabioetica. cfm.org.br/index.php/revista_bioetica/article/ view/745/776
Recebido: abril 16, 2021 Aprovado: novembro 18, 2021 